\title{
Vitamin D reduces the expression of collagen and key profibrotic factors by inducing an antifibrotic phenotype in mesenchymal multipotent cells
}

\author{
Jorge N Artaza ${ }^{1,2,3}$ and Keith C Norris ${ }^{1,3}$ \\ ${ }^{1}$ Department of Internal Medicine, Charles Drew University of Medicine \& Science, Los Angeles, California 90059, USA \\ ${ }^{2}$ Department of Biomedical Sciences, Charles Drew University of Medicine \& Science, Los Angeles, California 90059, USA \\ ${ }^{3}$ Department of Medicine, David Geffen School of Medicine at UCLA, Los Angeles, California 90024, USA \\ (Correspondence should be addressed to J N Artaza at Division of Endocrinology, Metabolism \& Molecular Medicine, Charles Drew University of Medicine \& \\ Science, 1731 East 120th Street, Los Angeles, California 90059, USA; Email: jorgeartaza@cdrewu.edu)
}

\begin{abstract}
Hypovitaminosis D is an important public health problem. Serum 25-hydroxyvitamin D (25-OHD) is now recognized as an independent predictor for cardiovascular and related diseases (CVD) as well as other chronic medical conditions. However, the biologic pathways through which these effects are mediated remain poorly understood. We hypothesized that exposing mesenchymal multipotent cells (MMCs) to the active form of vitamin D would increase the expression of selected antifibrotic factors that in turn would ameliorate the progression of chronic diseases. MMCs were primed with 5 -azacytidine to induce a fibrotic phenotype and then treated with active vitamin $\mathrm{D}(1,25 \mathrm{D})$ or ethanol $<0 \cdot 1 \%$ as vehicle in a time course manner $(30 \mathrm{~min}, 1,5$, and $24 \mathrm{~h}$, and for 4 and 7 days). The addition of 1,25D to MMCs promotes: a) increased expression and nuclear translocation of the vitamin D
\end{abstract}

receptor; b) decreased expression of TGFB1 and plasminogen activator inhibitor (SERPINE1), two well-known profibrotic factors; c) decreased expression of collagen I, III and other collagens isoforms; and d) increased expression of several antifibrotic factors such as BMP7 a TGFB1 antagonist, MMP8 a collagen breakdown inducer and follistatin, an inhibitor of the profibrotic factor myostatin. In conclusion, the addition of $1,25 \mathrm{D}$ to differentiated MMCs displays a decreased profibrotic signaling pathway and gene expression, leading to decrease in collagen deposition. This study highlights key mechanistic pathways through which vitamin D decreases fibrosis, and provides a rationale for studies to test vitamin D supplementation as a preventive and/or early treatment strategy for CVD and related fibrotic disorders.

Journal of Endocrinology (2009) 200, 207-221

\section{Introduction}

Hypovitaminosis D, as well as other chronic medical conditions, is increasingly recognized as an independent predictor factor for cardiovascular and related diseases (CVD; Casteels et al. 1998, Martins et al. 2007, Giovannucci 2008, Kovesdy et al. 2008, Wang et al. 2008). The biologic pathways through which these effects are mediated remain poorly understood, but may be linked to vitamin D regulation of related fibrotic pathways (Repo et al. 2007).

Fibrosis (progressive scarring) is often defined as an exaggerated wound-healing response due to chronic sustained injury, microtrauma, oxidative stress, endogenous or exogenous insults, autoimmunity, and other factors and is attributed to an excessive deposition of extracellular matrix components, mainly collagen (Wynn 2007). Fibrosis is not restricted to CVD and may underlie numerous chronic medical conditions such as progressive kidney disease, macular degeneration and others (Willis et al. 2006, Gharaee-Kermani et al. 2007, Henderson \& Iredale 2007) and, at the present time, there are limited effective treatments for these conditions (Wynn 2007). While chronic inflammation typically precedes fibrosis, there are distinct, independent inflammatory mechanisms that regulate fibrogenesis such as the deregulation of myofibroblast progenitor cell differentiation and myofibroblast collagen synthesis and extracellular matrix repair (Iredale 2007, Wynn 2007). Contrary to previous dogma, fibrosis can now be considered as a reversible and curable process (Fallowfield et al. 2006, Iredale 2007) when interventions can be initiated at earlier stages of the disease (Kisseleva \& Brenner 2006).

Recently, it has been clinically shown, that the administration of active vitamin D $(1,25 \mathrm{D})$, results in significant amelioration of chronic medical conditions such as chronic kidney disease and CVD (Kovesdy et al. 2008, Wolf et al. 2008). This effect may occur, in part, through attenuation of 
profibrotic, and proinflammatory pathways (Tan et al. 2006, 2007), although the basic mechanism by which vitamin $\mathrm{D}$ may exert these effects remains poorly understood.

Vitamin D is a lipid-soluble prohormone obtained from dietary sources or from de novo synthesis in the skin, as a result of u.v. light-induced photolytic conversion of 7-dehydrocholesterol to previtamin D3 followed by thermal isomerization to vitamin D3 (Brown 1998, Dusso \& Brown 1998, Feldman et al. 2005). The first step in the metabolic activation of vitamin D is hydroxylation of carbon 25 , occurring primarily in the liver. The second and more regulated step in vitamin $\mathrm{D}$ bioactivation is the formation of $1,25 \mathrm{D}\left(1 \alpha, 25-(\mathrm{OH})_{2} \mathrm{D}_{3}\right)$ also known as calcitriol, the active form of vitamin D, which occurs mainly in the kidney (Dusso et al. 2005) via the 25-hydroxyvitamin D-1 $\alpha$-hydroxylase enzyme. $1,25 \mathrm{D}$ activates the vitamin $\mathrm{D}$ receptor (VDR), a nuclear transcription factor of the steroid-retinoid nuclear receptor gene superfamily, ultimately promoting gene transcription (Carlberg et al. 2001, Zehnder et al. 2001). The VDR appears to be ubiquitous in the body, supporting the vitamin D endocrine system, which is involved in a wide range of physiological functions (Mathieu et al. 1994, Casteels et al. 1998, Malluche et al. 2002, Dusso et al. 2004).

In the present study we examined, in a time-course manner, using $\mathrm{C} 3 \mathrm{H} 10 \mathrm{~T} 1 / 2$ cells a multipotent mesenchymal cell line of mouse origin, the effects of $1,25 \mathrm{D}$ on the expression and nuclear translocation of VDR, the expression of SERPINE1 and TGFB1 (both well-known profibrotic factors), the changes in the expression of collagen I, collagen III, and other collagen isoforms and the expression of antifibrotic factors such as: BMP7, MMP8, and follistatin (Fst) by immunofluorescence, western blot, DNA microarrays and real-time PCR array analysis. C3H 10T1/2 cells have been shown by us and others to have the potential to differentiate into a variety of specialized cells such as osteocytes, chondrocytes, adipocytes, endothelial, and smooth muscle cells (Singh et al. 2003, Pittenger \& Martin 2004, Artaza et al. 2005), and they have been used to study the effects of $1,25 \mathrm{D}$ on cell proliferation and cell cycle (Brackman et al. 1993).

Recent studies have demonstrated that mesenchymal multipotent cells (MMCs) also possess the potential to differentiate along an endothelial lineage. Additionally, other studies have revealed the contribution of MMCs to the formation of new vessels and improvement in cardiac function (Pittenger \& Martin, 2004). Thus, MMCs may hold the potential to differentiate along endothelial lines and to be used for applications such as neovascularization and tissue engineering (Rabbany et al. 2003).

\section{Materials and Methods}

\section{Cell culture}

Mouse C3H 10T1/2 MMCs (ATCC, Manassas, VA, USA) were grown in DMEM with $10 \%$ dialyzed fetal bovine serum at $37^{\circ} \mathrm{C}$ and $5 \% \mathrm{CO}_{2}$ and then treated with $20 \mu \mathrm{M}$ $5^{\prime}$-azacytidine (AZCT) for 2 days to induce differentiation by epigenetic changes (Singh et al. 2003, Artaza et al. 2005, Schmittwolf et al. 2005) and to promote a fibrotic phenotype (Adams et al. 2005, Artaza et al. 2008a,b).

Cells were split in a 1:2 ratio, allowed to recover for 2 days, and replated at $60-70 \%$ confluence in T75 flasks, eight-well chamber slides or six-well plates. The next day, cells were incubated with or without $100 \mathrm{nM}$ of 1,25D (SigmaAldrich) dissolved in less than $0 \cdot 1 \%$ ethanol as vehicle in DMEM $10 \%$ dialyzed fetal bovine serum and incubated for $30 \mathrm{~min}, 1,5$ and $24 \mathrm{~h}$, and for 4 and 7 days. Control groups were incubated with $0 \cdot 1 \%$ ethanol in DMEM $10 \%$ dialyzed fetal bovine serum. Because of the short half-life of 1,25D, the cell culture media with and without 1,25D (100 nM) was replaced every 2 days.

\section{Detection of VDR by immunofluorescence}

After the corresponding incubation time with or without $1,25 \mathrm{D}$, the cells were washed thrice with PBS and fixed by immersion in $2 \% p$-formaldehyde. Cells were blocked with normal goat serum, and incubated with a rabbit polyclonal antibody against VDR at a dilution of 1:50 (Santa Cruz Biotechnology, Santa Cruz, CA, USA). The detection was followed by a $1 / 200$ dilution of anti-rabbit biotinylated secondary antibody (Calbiochem, La Jolla, CA, USA), followed by Streptavidine-Texas Red $(10 \mu \mathrm{g} / \mathrm{ml}$; Vector Labs, Burlinghame, CA, USA). After several washes, cells were counterstained with DAPI (Vector Labs). The slides were detached and mounted in 'prolong anti-fade' (Molecular Probes, Eugene, OR, USA) and were examined under a Leica DMLB fluorescence microscope equipped with the appropriate filters. The merge image was obtained by fusing the red and the blue filters pictures (Artaza et al. 2002). Fields were photographed with a SPOT-RT digital camera and acquisition software (Diagnostic Instruments, Sterling Heights, MI, USA).

Negative controls were done by either omitting the first antibody or using a rabbit non-specific IgG (Singh et al. 2003, Artaza et al. 2005, 2008a,b). To ensure specific staining of VDR antibody, a negative control was done by pre-absorbing the primary VDR antibody with $1 \mu \mathrm{M}$ VDR specific peptide, SC1008P (Santa Cruz Biotechnology), after $1 \mathrm{~h}$ incubation at RT the mixture was centrifuged at full speed for $15 \mathrm{~min}$ and the supernatant was used as a primary antibody at the same dilution used previously for the experiment. No positive staining was observed in the cells by immunofluorescence in this negative control.

\section{Immunocytochemical analyses of profibrotic markers and collagen}

After the corresponding incubation time with or without $1,25 \mathrm{D}$, the cells were washed thrice with PBS and fixed by immersion in $2 \% p$-formaldehyde, quenched with $\mathrm{H}_{2} \mathrm{O}_{2}$, blocked with normal goat or horse serum and incubated with 
the following antibodies: a) SERPINE1 (1:200) (Abcam Inc., Cambridge, MA, USA), b) TGFB1 (1:200) Promega Corporation), c) collagen I (1:100) (Abcam Inc.) and d) collagen III (1:100) Abcam Inc).

Detection was based on a secondary biotinylated antibody (1:200), followed by the addition of the streptavidin-HRP ABC complex (1:100), Vectastain (Elite ABC System, Vector Laboratories) and 3,3'-diaminobenzidine and $\mathrm{H}_{2} \mathrm{O}_{2}$ mixture (Sigma). The cells were counterstained with Meyer's hematoxylin (Sigma). In negative controls, we either omitted the first antibody or used a rabbit non-specific IgG. (Artaza et al. 2002, 2005, 2008a,b, Singh et al. 2003).

\section{Quantitative image analysis}

In all cases, the immunoreactivity was quantified by image analysis using ImagePro-Plus 5.1 software (Media Cybernetics, Silver Spring, MD, USA). After the images were calibrated for background lighting, integrated optical density (IOD) results were proportional to the mean optical density per area. IOD determines the amount of immunoreactive antigen present in each cell. The IOD values expressed in arbitrary units were determined in at least 20 pictures per treatment and time points. The results expressed as mean \pm S.E.M. represent the average of three independent experiments (Singh et al. 2003, Artaza et al. 2005, 2008a,b).

\section{Nuclear and cytoplasmic fraction extraction}

Of $5^{\prime}$-azacytidine pre-treated cells grown in T75 cell culture flasks were incubated with or without 1,25D (100 nM) for $24 \mathrm{~h}, 4$ and 7 days. At the end of the corresponding incubation times, cells were washed thrice with PBS and detached with trypsin, $2 \cdot 5 \%$. Cells were centrifuged and the cell number was adjusted to $2 \times 10^{6}$ cells. Nuclear and cytoplasmic extraction fractions were done using NE-PER Nuclear and Cytoplasmic Extraction Reagents (Pierce Biotechnology, Rockford, IL, USA) following the manufacturer's instructions. Protein concentrations in both fractions were determined and adjusted. The cytoplasmic and nuclear fractions were subjected to western blot analysis for VDR localization/expression and to ensure extraction efficiency GAPDH was determined in each fraction.

\section{Western blot and densitometry analysis}

Cell lysates (30-40 $\mu \mathrm{g}$ protein) were subjected to western blot analyses by $4-15 \%$ Tris-HCl PAGE (Bio-Rad) using a monoclonal antibody for glyceraldehide-3-phosphate dehydrogenase (GAPDH) (1/10 000) (Chemicon International, Temecula, CA, USA). Polyclonal antibodies were used for VDR (1/500), (Santa Cruz Biotechnology Inc.), TGFB1 (1/1000) (Promega Corporation), and SERPINE1 $(1 / 1000)$ (Abcam Inc). The washed membranes were incubated with $1 / 2000$ dilution (anti-rabbit) or $1 / 3000$ dilution (anti-mouse) of secondary antibody linked to HRP
(GE Healthcare, Bucks, UK) respectively. Immunoreactive bands were visualized using the ECL plus western blotting chemiluminescence detection system (Amersham Biosciences). The densitometry analysis of the bands was done with the Scion Image software beta 4.02 (Scion Corp., Frederick, MD, USA).

\section{Real-time quantitative PCR}

After $24 \mathrm{~h}$ and 4 days incubation with or without 1,25D, total RNA was extracted using Trizol-Reagent (Invitrogen) and equal amounts $(1 \mu \mathrm{g})$ of RNA were reverse transcribed using a RNA PCR kit (Applied Biosystems, Foster City, CA, USA). The locations of forward/reverse PCR primers for real-time RT-PCR are as follows: VDR region 575-597/626641 on BC074818.2 (67 bp). Mouse gene PCR primer sets (RT2) were purchased from SABiosciences (Frederick, MD, USA). The Qiagen Sybr Green PCR kit with HotStar Taq DNA polymerase (Qiagen) was used with i-Cycler PCR thermocycler and fluorescent detector lid (Bio-Rad).

The protocol included melting for $15 \mathrm{~min}$ at $95^{\circ} \mathrm{C}, 40$ cycles of three-step PCR including melting for $15 \mathrm{~s}$ at $95^{\circ} \mathrm{C}$, annealing for $30 \mathrm{~s}$ at $58{ }^{\circ} \mathrm{C}$, elongation for $30 \mathrm{~s}$ at $72{ }^{\circ} \mathrm{C}$ with an additional detection step of $15 \mathrm{~s}$ at $81^{\circ} \mathrm{C}$, followed by a melting curve from 55 to $95^{\circ} \mathrm{C}$ at the rate of $0.5^{\circ} \mathrm{C}$ per $10 \mathrm{~s}$. We confirmed that inverse derivatives of melting curves show sharp peaks for VDR at $83^{\circ} \mathrm{C}$ and $\mathrm{GAPDH}$ at $87^{\circ} \mathrm{C}$, indicating the correct products. Samples of $25 \mathrm{ng}$ cDNA were analyzed in triplicate in parallel with GAPDH controls; standard curves (threshold cycle versus log pg cDNA) were generated by $\log$ dilutions of from $0 \cdot 1 \mathrm{pg}$ to $100 \mathrm{ng}$ standard cDNA (reverse-transcribed mRNA from C3H 10T1/2 cells in Growth Medium). Experimental mRNA starting quantities were then calculated from the standard curves and averaged using i-Cycler, iQ software as described previously. The ratios of marker experimental gene (e.g., VDR mRNA) to GAPDH mRNA were tallied and normalized to control (untreated) samples as 100\%. (Singh et al. 2003, Artaza et al. 2008a,b).

\section{DNA microarray analysis of TGFB1/BMP target genes}

Total cellular RNA was isolated with Trizol-Reagent from C3H 10T1/2 cells undergoing differentiation with AZCT, and treated with or without 1,25D (100 nM) for 4 days. Isolated RNA was subjected to cDNA gene arrays (GEArray $\mathrm{Q}$ Series, TGFB1/BMP signaling pathway gene array (MM-023) and osteogenesis gene array (MM-026) analysis (SABiosciences Corp). This series of mice TGFB1/BMP signaling pathway gene arrays is designed to study the genes involved in TGFB1/BMP signaling pathway and in the process of osteogenic differentiation. Biotin-labeled cDNA probes were synthesized from total RNA, denatured, and hybridized overnight at $60^{\circ} \mathrm{C}$ in GEHybridization solution to membranes spotted with TGFB1/BMP signaling pathway specific genes, as well as with genes involved in the regulation 
of osteogenic differentiation. Membranes were washed, and chemiluminescent analysis was performed per the manufacturer's instructions. Raw data were analyzed using GEArray Expression Analysis Suite (SABiosciences Corp). Fold changes in relative gene expression were presented after background correction and normalization with a housekeeping gene. (Artaza et al. 2008a,b).

Confirmation of DNA microarray analysis by $R T^{2}$ profiler $P C R$ array analysis of TGFB1/BMP and osteogenesis target genes

$\mathrm{RT}^{2}$ profiler PCR SABiosciences analyses of TGFB1/BMP and osteogenesis target genes were applied in triplicates in order to confirm the GE Array data. Aliquots of total cellular RNA isolated with Trizol-Reagent from C3H 10T1/2 cells undergoing differentiation with AZCT were treated with or without 1,25D (100 nM) for 1 and 4 days. They were then subjected to reverse transcription, and the resulting cDNA was analyzed by: $\mathrm{RT}^{2}$ profiler PCR mouse TGFB1/BMP signaling pathway (APM-035A) and by $\mathrm{RT}^{2}$ profiler PCR mouse osteogenesis (AMM-026D) (SABiosciences Corp). This series of mice TGFB1/BMP and osteogenesis signaling pathway gene arrays is designed to study the genes involved in upstream and downstream of TGFB1/BMP signaling and osteogenesis differentiation respectively. Each array contains a panel of 84 primer sets related to the TGFB1/BMP signaling genes plus five housekeeping genes and two negative controls. Real time PCRs were performed as follows: melting for $10 \mathrm{~min}$ at $95^{\circ} \mathrm{C}$, 40 cycles of two-step PCR including melting for $15 \mathrm{sec}$ at $95^{\circ} \mathrm{C}$, annealing for $1 \mathrm{~min}$ at $60^{\circ} \mathrm{C}$. The raw data were analyzed using the $\Delta \Delta C_{\mathrm{t}}$ method following the manufacturer's instructions (SABiosciences Corp.; Artaza et al. 2008a,b).

\section{Statistical analysis}

All data are presented as mean \pm S.E.M. and between-group differences were analyzed using ANOVA. If the overall ANOVA revealed significant differences, then pairwise comparisons between groups were performed by NewmanKeuls multiple comparison test. All comparisons were two-tailed, and $P<0 \cdot 05$ was considered statistically significant. The in vitro experiments were repeated thrice, and data from representative experiments are shown. Specifically, the DNA microarrays tests were done twice and the results confirmed by $\mathrm{RT}^{2}$ Profiler PCR arrays in triplicates and in some cases by qRT-PCR also in triplicate.

\section{Results}

Time course of expression and nuclear translocation of VDR in C3H 10T1/2 MMCs after incubation with 1,25 D

To determine whether the expression of VDR in our multipotent cell cultures is present and induced upon incubation with $1,25 \mathrm{D}$, experiments using immunofluorescence, western blot and real-time PCR were carried out at different time points. C3H 10T1/2 cells pre-treated with AZCT were incubated with or without 1,25D (100 nM) for $30 \mathrm{~min}, 1,5$, and $24 \mathrm{~h}$, and 4 , and 7 days. The dose of $1,25 \mathrm{D}$ used for these studies was derived after preliminary studies on the effects at 3 and 4 days exposure to $0,10,25,50,100$, and $500 \mathrm{nM} 1,25 \mathrm{D}$ on proliferation of C3H 10T1/2 multipotent cells. In those preliminary studies, comparison of $1,25 \mathrm{D}$ at 10 and $50 \mathrm{nM}$ without $1,25 \mathrm{D}$ had no effect, while there was a dose-dependent significant decrease in cell proliferation with increasing doses that peaked at 1,25D $(100 \mathrm{nM}$; not shown; Artaza et al. 2008a,b). The incubation with AZCT has no effect on the expression of VDR in the $\mathrm{C} 3 \mathrm{H} 10 \mathrm{~T} 1 / 2$ multipotent cell line (not shown).

By immunocytochemical (ICC) staining (Fig. 1) under basal conditions (no 1,25D), VDR immunofluorescence (red) was barely detected in the cell culture. After $30 \mathrm{~min}$ incubation with $1,25 \mathrm{D}$, VDR expression was clearly increased in the cytoplasm and nuclear compartment. A similar observation was made at 1 and $5 \mathrm{~h}$ (Fig. 1). By contrast, after $24 \mathrm{~h}, 4$ and 7 days of continuous 1,25D incubation, most of the red-fluorescence staining was observed in the nucleus (Fig. 1). The counterstaining with DAPI and the merge pictures confirm the nuclear localization of VDR in some cases, and the presence of the cells in the cell culture in others (no $1,25 \mathrm{D}$ incubation).

The increased expression of VDR after 1,25D incubation was further confirmed at $24 \mathrm{~h}$ and at 4 days by real-time PCR (qRT-PCR; Fig. 2). VDR mRNA expression increased by 3.3- and 4-fold at 1 and 4 days respectively compared with the controls without addition of $1,25 \mathrm{D}$.

Furthermore, the increased expression of VDR after 1,25D incubation was also confirmed by western blot analysis using whole cell culture homogenates incubated with or with out 1,25D (100 nM) at $24 \mathrm{~h}, 4$ and 7 days (Fig. 3A). The densitometry analysis shows an increase of VDR expression upon incubation with $1,25 \mathrm{D}$ at $24 \mathrm{~h}, 4$ and 7 days by $1 \cdot 75-$, $2 \cdot 2-$ and twofold respectively.

In order to confirm the nuclear translocation of VDR after $1,25 \mathrm{D}$ incubation previously shown by immunofluorescence, nuclear and cytoplasmic fractionation were performed after $24 \mathrm{~h}, 4$ and 7 days incubation with or without 1,25D $(100 \mathrm{nM})$, and the resulting nuclear and cytoplasmic fractions were analyzed by western blot. Figure $3 \mathrm{~B}$ shows that the expression of VDR in the control group (no 1,25D addition) was negligible in both cytoplasmic and nuclear fraction at all incubation time points. $1,25 \mathrm{D}$ addition induces a moderate expression of VDR in the cytoplasmic compartment but a much higher expression in the nuclear compartment at $24 \mathrm{~h}$. Incubation with 1,25D for 4 and 7 days shows an exclusive nuclear localization in agreement with the previous observations by immunofluorescence.

To verify the purity of the subcellular fractionation, the membrane was stripped and reprobed with anti-GAPDH antibody. Expression of GAPDH (a cytoplasmic protein) was almost exclusively localized in the cytoplasmic fraction. 


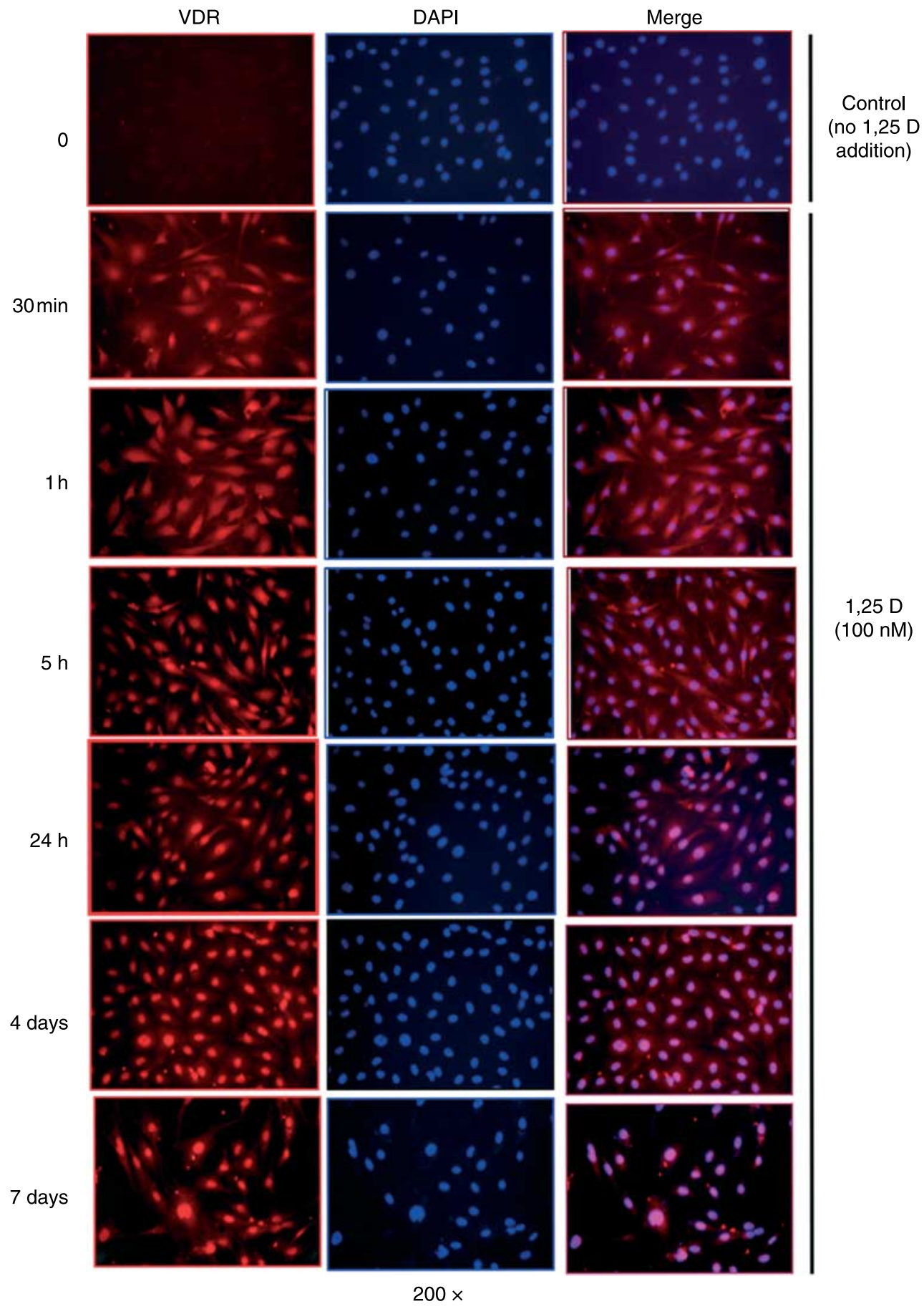

Figure 1 Time course of the expression and nuclear translocation of vitamin D receptor (VDR) upon incubation with 1,25D in mesenchymal multipotent C3H 10T1/2 cells. Cultures of C3H 10T1/2 cells were treated with $20 \mu \mathrm{M}$ azacytidine for 2 days to induce fibrosis and 2 days later were incubated with or without 1,25D (100 $\mathrm{nM})$ at different time points: $30 \mathrm{~min}, 1,5$, and $24 \mathrm{~h}$, and for 4 and 7 days. Cells were cultured on eight-well removable chambers slides and subjected for immunofluorescence using a polyclonal antibody for VDR followed by a Texas Red-conjugated secondary antibody (red). Cells were counterstained with DAPI (blue) to show nuclear staining. Merge pictures were done combining the red and blue pictures together (purple) and in order to show nuclear localization of VDR. Magnification $=200 \times$. 


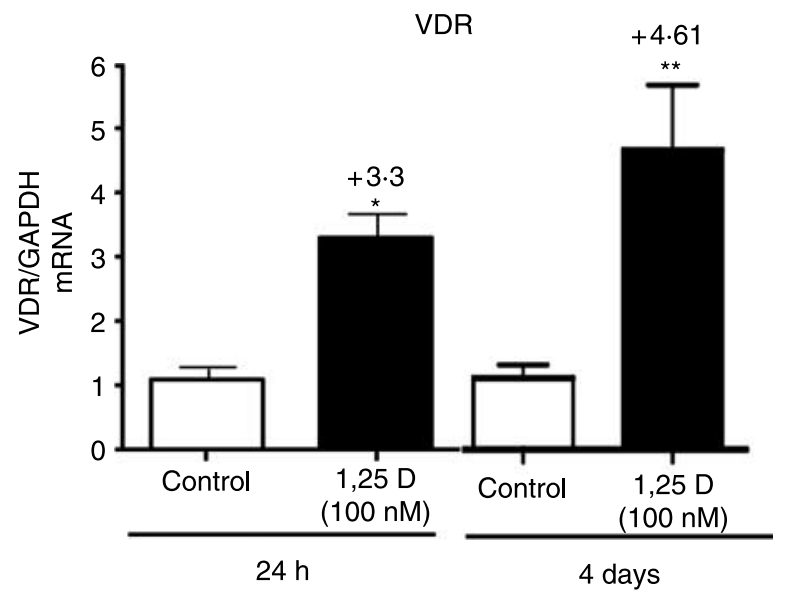

Figure 2 Transcriptional upregulation of mRNA VDR upon incubation with 1,25D in mesenchymal multipotent C3H 10T1/2 cells. Cultures of $\mathrm{C} 3 \mathrm{H} 10 \mathrm{~T} 1 / 2$ cells were treated as in Fig. 1 and incubated with or without 1,25D (100 nM) for $24 \mathrm{~h}$ and 4 days. Total RNA isolation followed by real-time RT-PCR was applied and normalized by GAPDH housekeeping gene. Mean \pm s.E.M. corresponds to experiments done in triplicates. ${ }^{*} P<0 \cdot 05,{ }^{* *} P<0 \cdot 01$.

\section{1,25D induces an antifibrotic phenotype in C3H 10T1/2 multipotent cells due to translational downregulation of profibrotic factors}

Incubations with $1,25 \mathrm{D}(100 \mathrm{nM})$ for $24 \mathrm{~h}$ and 4 days clearly decreased the intensity of the ICC staining of two selected profibrotic factors, TGFB1 and SERPINE1. Figure $4 \mathrm{~A}$ and $\mathrm{B}$ (left panels) shows the decreased expression of TGFB1 after $24 \mathrm{~h}$ and 4 days incubation with 1,25D. Our visual inspection was confirmed by quantitative image analysis Fig. 4A and B (right panels) where TGFB1 expression was significantly decreased by $67 \%$ with respect to the control $(P<0 \cdot 001)$ at $24 \mathrm{~h}$ and by $50 \%$ with respect to the control $(P<0 \cdot 01)$ at 4 days. The ICC results were further confirmed by western blot at $24 \mathrm{~h}, 4$ and 7 days showing that the levels of expression of TGFB1 were dramatically reduced after 7 days of continuous incubation with 1.25D Fig. 4C.

The same effect was observed on the expression of another key profibrotic factor SERPINE1 upon incubation with $1,25 \mathrm{D}$. Figure $5 \mathrm{~A}$ and $\mathrm{B}$ shows by ICC that SERPINE1 expression was reduced by $55 \%$ with respect to the control $(P<0.001)$ at $24 \mathrm{~h}$ and by $52 \%$ after 4 days incubation with $1,25 \mathrm{D}(P<0 \cdot 001)$. The ICC results for SERPINE1 were further confirmed by western blot at $24 \mathrm{~h}, 4$ and 7 days of continuous incubation with $1 \cdot 25 \mathrm{D}$ Fig. 5C.

\section{$1,25 \mathrm{D}$ decreases the expression of collagen I and collagen III in C3H 10T1/2 multipotent cells}

C3H 10T1/2 cells pre-treated with AZCT shows high expression of collagen I as shown in Fig. 6A and B by ICC at low and high magnification. Addition of $1,25 \mathrm{D}$ to the cell culture for $24 \mathrm{~h}$ and 4 days reduced the expression of collagen I in the cells by $65 \%$ with respect to the control $(P<0 \cdot 001)$ at $24 \mathrm{~h}$ and by $68 \%$ with respect to the control $(P<0 \cdot 001)$ at 4 days determined by quantitative image analysis.

Figure 7 shows similar results regarding the expression of collagen III under the same conditions. Addition of $1,25 \mathrm{D}$ to the cell culture for $24 \mathrm{~h}$ and 4 days reduced the expression of collagen III in the cells by $75 \%$ with respect to the control $(P<0 \cdot 001)$ at $24 \mathrm{~h}$ and by $68 \%$ with respect to the control $(P<0 \cdot 001)$ at 4 days determined by quantitative image analysis.

\section{Effects of $1,25 D$ on the transcriptional regulation of pro and antifibrotic factors}

The antifibrotic effect of 1,25 D on the C3H 10T1/2 cells was also analyzed at the transcriptional level applying the mouse TGFB1/BMP signaling pathway gene array (MM-023) and the mouse osteogenesis gene array (MM-026). Figure 8 shows one of the two sets of membranes for each DNA microarray: TGFB1/BMP signaling pathway gene array (MM-023) (Fig. 8A) and mouse osteogenesis gene array (MM-026) (Fig. 8B) performed after 4 days incubation with or without $1,25 \mathrm{D}$. Some of the genes that showed differential RNA expression between the 1,25D-treated and -untreated cells are indicated by circles (Fig. 8A and B) and were selected for the table shown in Fig. 8C, where the computer-generated ratios of spot intensities, normalized by housekeeping genes are tabulated. DNA microarray analysis shows an increase in the expression of the BMP4 as was expected due to the role of $1,25 \mathrm{D}$ in the osteogenic pathway. The antifibrotic effect of $1,25 \mathrm{D}$ was evident by the reduction of several collagen types and isoforms such as procollagen, type $\mathrm{I} \alpha 1,2$; procollagen, type III $\alpha 1$; procollagen, type V $\alpha 1$, and procollagen, type VI $\alpha 1$,2. In addition, 1,25D increases the expression of several antifibrotic factors such as: BMP7, MMP8, and follistatin a well-known myostatin inhibitor.

This DNA microarray panel has only some of the fibrotic genes - essentially collagens, BMP members - that transduce signals triggered by the members of the TGFB1 family. For this reason, and in order to confirm and expand the DNA microarray data, we performed real-time PCR arrays using the RT2 profiler PCR SuperArray set of primers and procedures. The ratios for triplicate determinations are shown in Table 1 for $24 \mathrm{~h}$ and 4 days after incubation with 1,25D. The agreement between the ratios obtained by DNAmicroarrays and RT-PCR is in general adequate and provides a reasonable assessment of up- and downregulation. The results of the RT-PCR arrays confirm and provide additional data related to the antifibrotic effects of 1,25D. A substantial decrease in the mRNA expression of numerous collagen isoforms such as: collagen $I \alpha 1$ and $\alpha 2$, collagen II $\alpha 1$, collagen III $\alpha 1$, collagen $\mathrm{V} \alpha 1$, collagen VI $\alpha 1$ and $\alpha 2$, collagen X $\alpha 1$, collagen XII $\alpha 1$, and collagen $\mathrm{XIV} \alpha 1$ was found, after only $24-\mathrm{h}$ incubation with $1,25 \mathrm{D}$. 

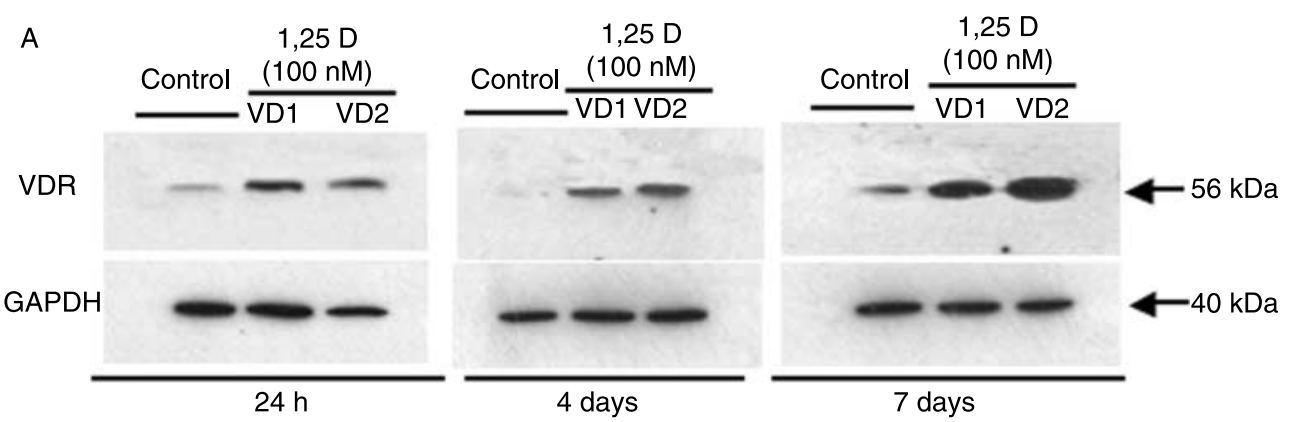

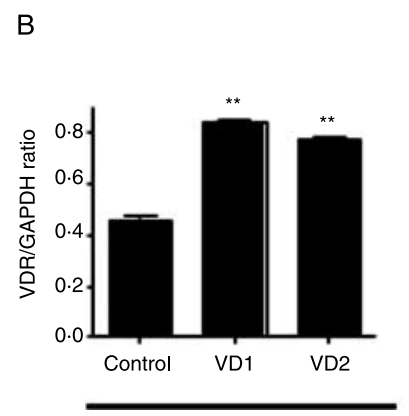

$24 \mathrm{~h}$

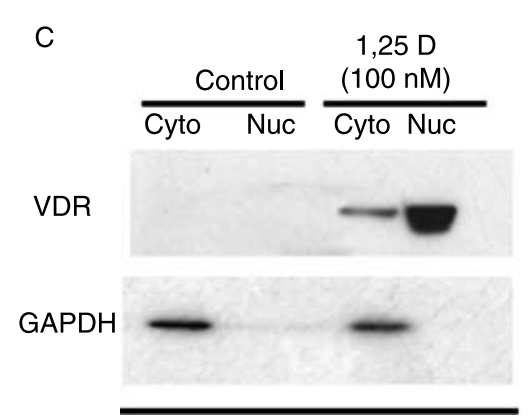

$24 \mathrm{~h}$

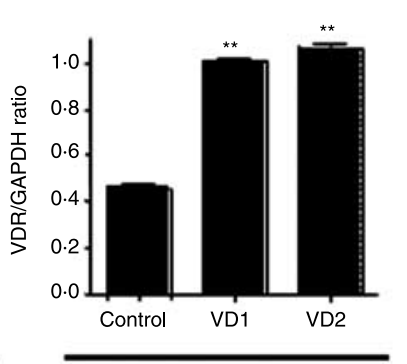

4 days

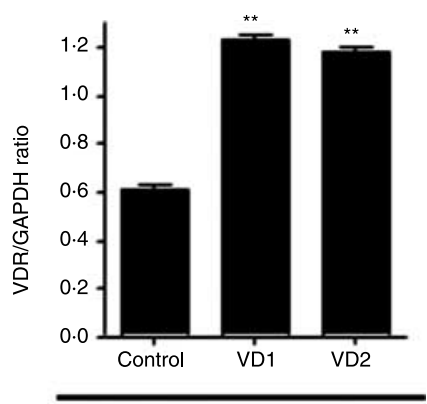

7 days

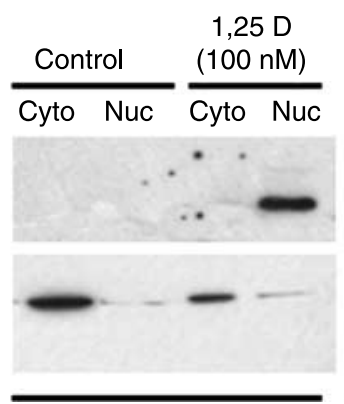

4 days

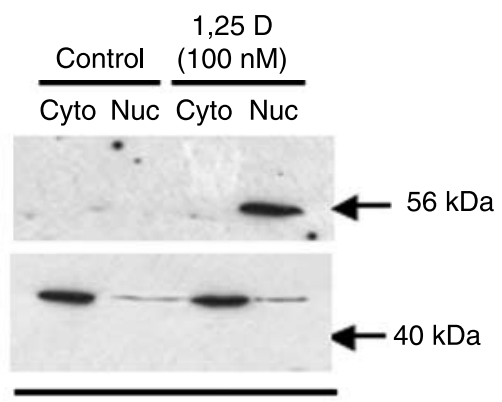

7 days

Figure 3 Translational upregulation of VDR expression and nuclear translocation upon incubation with 1,25D in mesenchymal multipotent C3H 10T1/2 cells. Cultures of C3H 10T1/2 cells were treated as in Fig. 1 and incubated with or without 1,25D (100 nM) for $24 \mathrm{~h}, 4$ and 7 days. Western blot immunoanalysis was performed in the whole extracts for each time point (A, top panel) and the corresponding quantitative densitometry analysis, $* * P<0 \cdot 01$

(A, bottom panel). Distribution of VDR protein in subcellular fractions (B) The nuclear and cytoplasmic fractions were isolated and subjected to western immunoblot analysis for VDR as described in the text. The same membrane in each case was stripped and reprobed with anti-GAPDH antibody to verify the purity of the subcellular fractionation.

In addition, activation of the BMP signaling pathway was found as it is shown by the increase mRNA expression of Bmp4 and BMP6 (Table 1).

Table 1 also confirmed that incubation with $1,25 \mathrm{D}$ at $24 \mathrm{~h}$ and 4 days induced gene expression of selected antifibrotic factors such as: Mmp8 (metalloproteinase) a collagen breakdown inducer; Bmp7 an antagonist of transforming growth factor- $\beta$-mediated renal fibrosis; and follistatin, an inhibitor of the profibrotic factor myostatin. The difference in ratios between DNA microarrays and real-time PCR arrays reflects the fact that the real-time PCR arrays are much more sensitive than the DNA microarrays.

\section{Discussion}

The data presented in this manuscript to the best of our knowledge constitute the first demonstration that $1,25 \mathrm{D}$ also known as calcitriol, the physiologically active form of vitamin $\mathrm{D}$, promotes an antifibrotic phenotype in $\mathrm{C} 3 \mathrm{H}$ 10T1/2 cells through the increased expression and nuclear translocation of VDR. In our MMC line model, incubation with $1,25 \mathrm{D}$ stimulates de novo synthesis of VDR within $30 \mathrm{~min}$ to $1 \mathrm{~h}$ upon incubation, reaching maximal induction between 5 and $24 \mathrm{~h}$. There were parallel changes in VDR specific mRNA levels indicating that the upregulation 
A

$400 x$

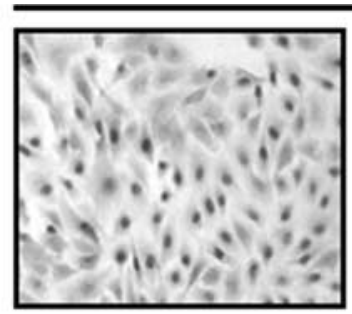

$24 \mathrm{~h}$

B

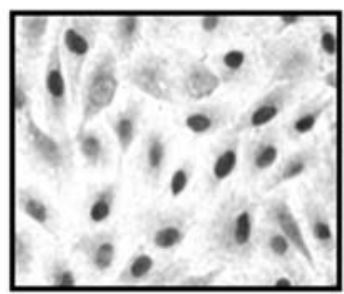

Control

4 days
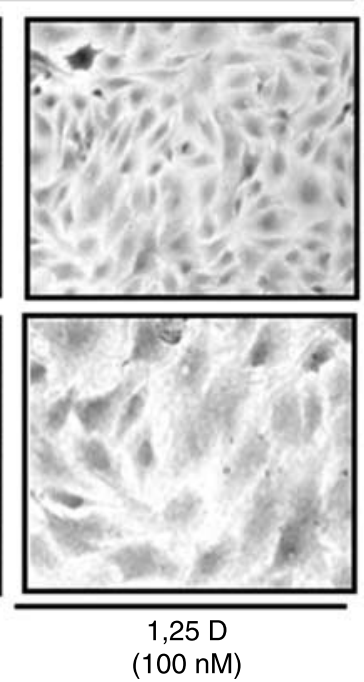

(100 nM)

$200 x$
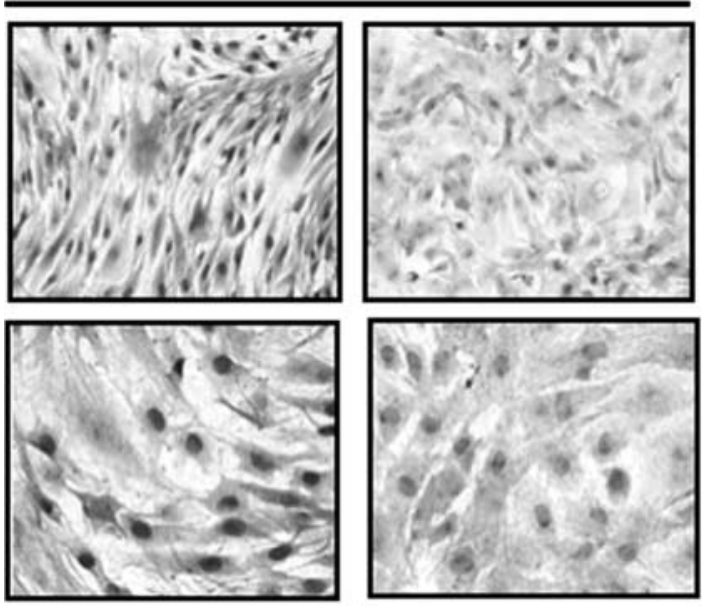

Control

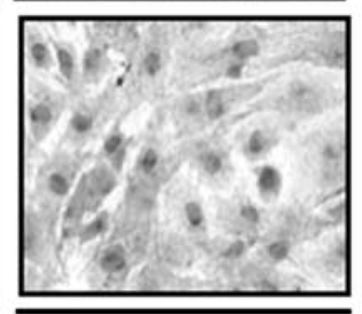

1,25 D

$(100 \mathrm{nM})$

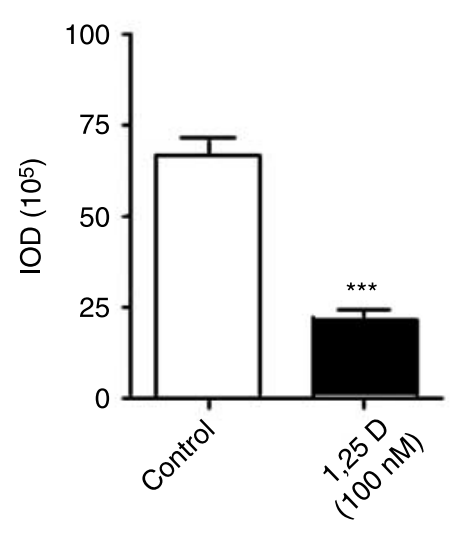

TGF 11

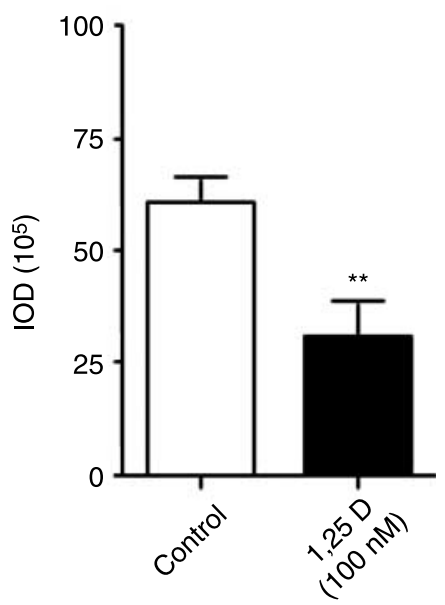

C
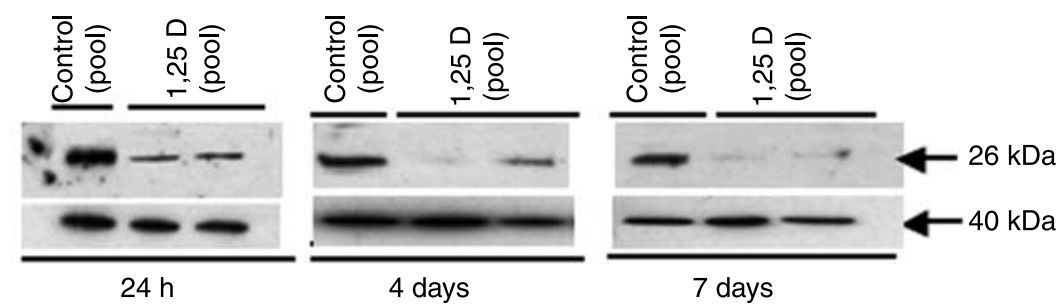

Figure 4 Effects of 1,25D on the expression of the profibrotic marker TGFB 1 in C3H 10T1/2 cells. Cultures of C3H 10T1/2 cells were treated as in Fig. 1 and incubated with or without 1,25D (100 nM) for $24 \mathrm{~h}, 4$ and 7 days. Immunocytochemistry for TGFB1 were performed at $24 \mathrm{~h}$ (A) and 4 days (B) on eight-well removable chambers slides. Mean \pm S.E.M. corresponds to experiments done in triplicates of the integrated optical density (IOD) by quantitative image analysis. ${ }^{* *} P<0 \cdot 01,{ }^{* * *} P<0 \cdot 001$. (C) Western blot analysis were performed with an anti-TGFB1 antibody to confirm the results obtained at $24 \mathrm{~h}, 4$ and 7 days using a pool of cells done in triplicates from two different experiments. The same membrane was stripped and reprobed with anti-GAPDH antibody (housekeeping gene). 
A
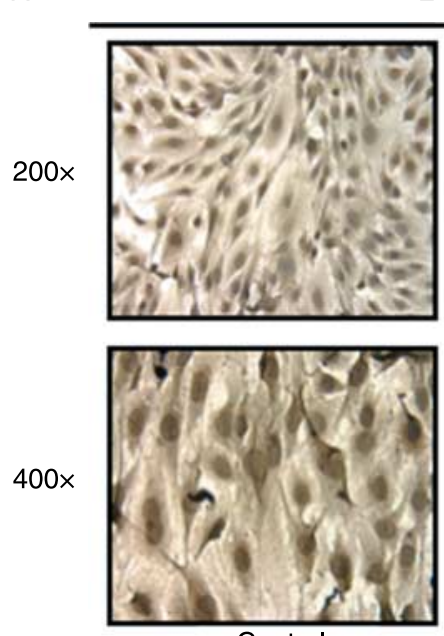

Control
$24 \mathrm{~h}$
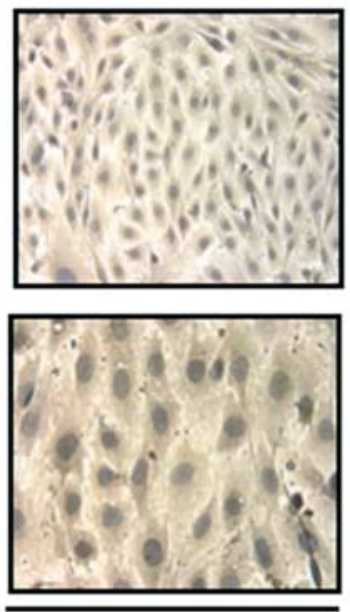

$1,25 \mathrm{D}$

$(100 \mathrm{nM})$

B

4 days

$200 \times$

$400 x$
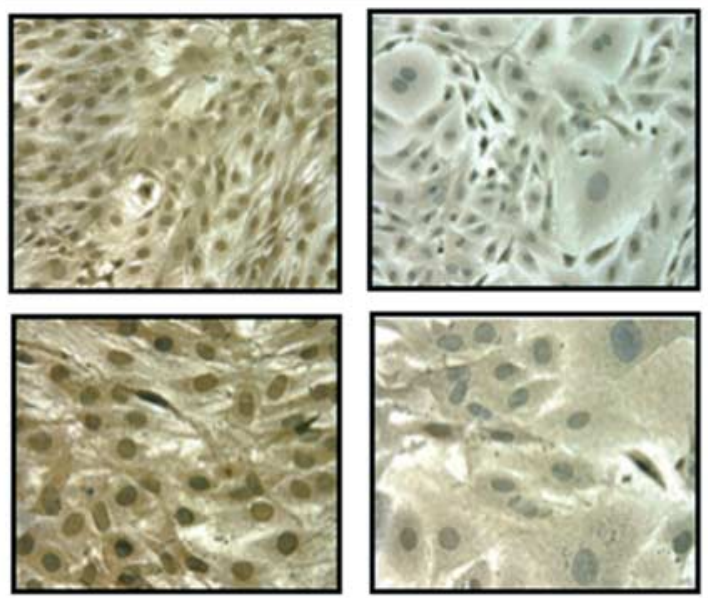

Control

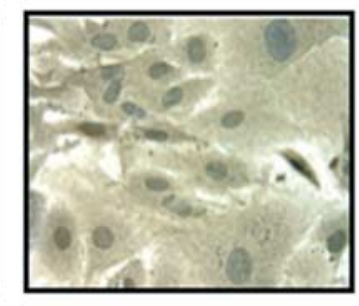

$1,25 \mathrm{D}$

$(100 \mathrm{nM})$

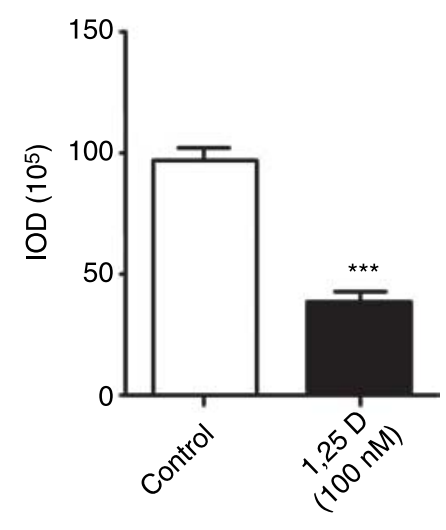

SERPINE1

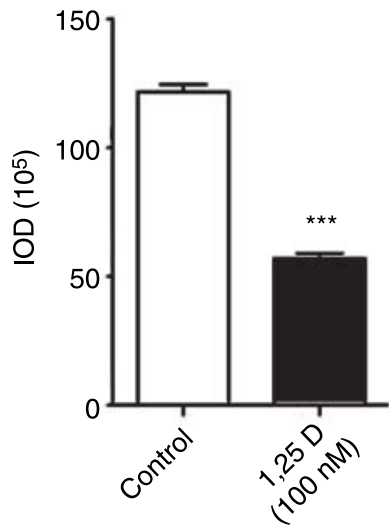

C

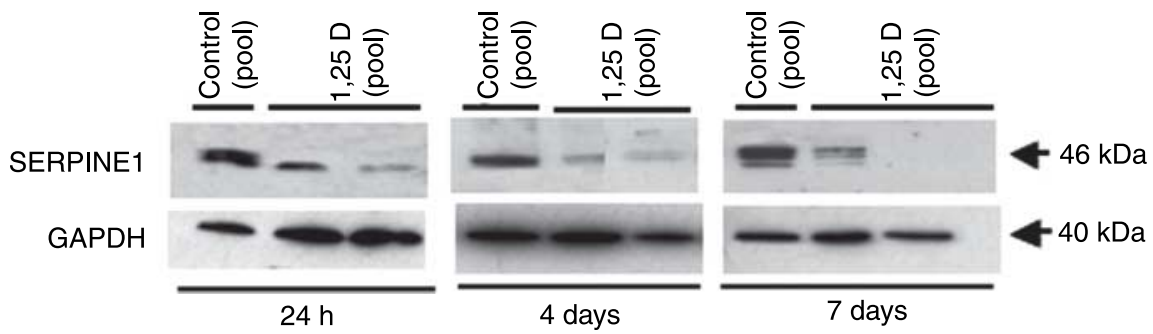

Figure 5 Effects of 1,25D on the expression of the profibrotic marker SERPINE1 in C3H 10T1/2 cells. Cultures of $\mathrm{C} 3 \mathrm{H} 10 \mathrm{~T} 1 / 2$ cells were treated as in Fig. 1 and incubated with or without 1,25D (100 nM) for $24 \mathrm{~h}, 4$ and 7 days. Immunocytochemistry for SERPINE1 were performed at $24 \mathrm{~h}$ (A) and 4 days (B) on eight-well removable chambers slides. Mean \pm S.E.M. corresponds to experiments done in triplicates of the integrated optical density (IOD) by quantitative image analysis $* * * P<0 \cdot 001$. (C) Western blot analysis were performed with an anti-SERPINE1 antibody to confirm the results obtained at $24 \mathrm{~h}, 4$ and 7 days using a pool of cells done in triplicates from two different experiments. The same membrane was stripped and reprobed with anti-GAPDH antibody (housekeeping gene). 
A

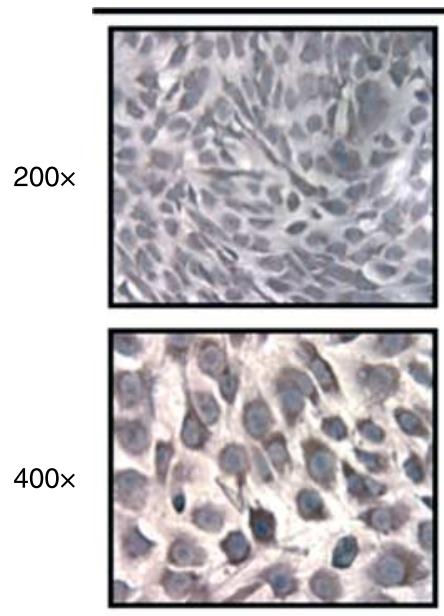

Control
$24 \mathrm{~h}$
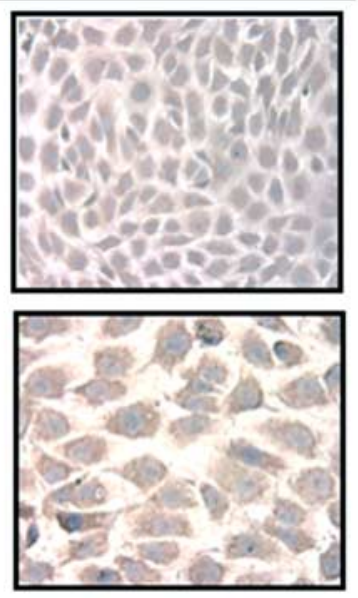

$1,25 \mathrm{D}$

$(100 \mathrm{nM})$
B
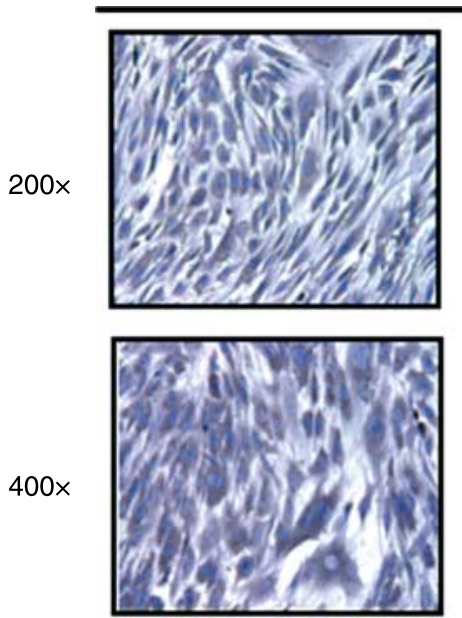

Control
4 days
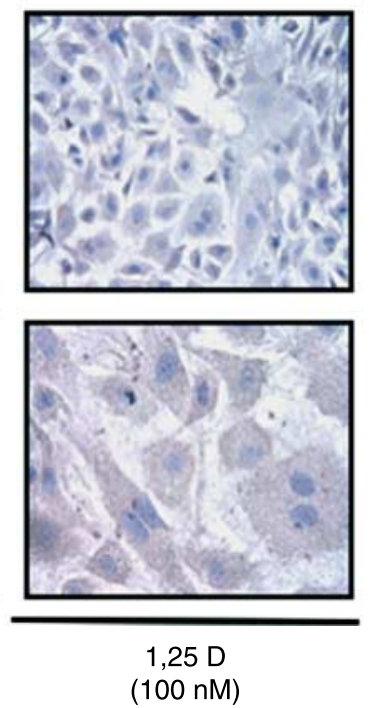

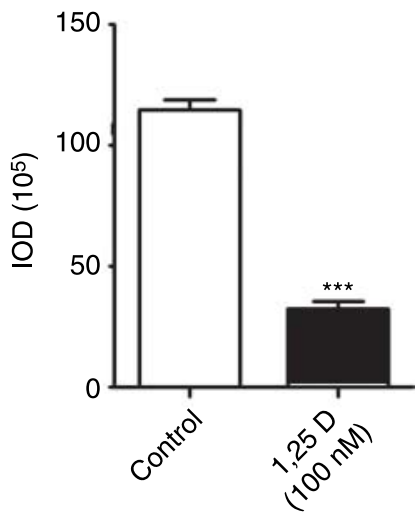

Collagen I

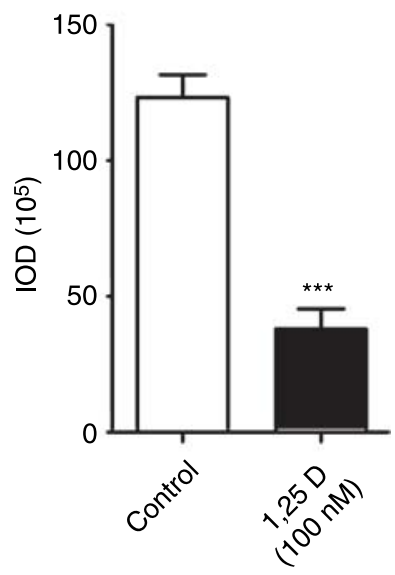

Figure 6 Effects of 1,25D on the expression of collagen I in C3H 10T1/2 cells. Cultures of C3H 10T1/2 cells were treated as in Fig. 1 and incubated with or without 1,25D $(100 \mathrm{nM})$ for $24 \mathrm{~h}$ and 4 days. Immunocytochemistry for collagen I were performed at $24 \mathrm{~h}$ (A) and 4 days (B) on eight-well removable chambers slides. Mean \pm S.E.M. corresponds to experiments done in triplicates of the integrated optical density (IOD) by quantitative image analysis $* * * P<0 \cdot 001$.

of VDR is dependent on de novo mRNA synthesis. Our finding that $1,25 \mathrm{D}$ reduces the expression of TGFB1 and SERPINE1 (two well-known profibrotic factors; Li et al. 2004, Mauviel 2005, Eddy \& Fogo 2006) is consistent with that of Wu-Wong et al. (2006) who demonstrated that vitamin $\mathrm{D}$ analogs downregulated SERPINE1 in coronary smooth cells, and with that of Tan et al. (2006), who showed that paricalcitol reduced renal TGFB1 in unilateral ureteral obstructed rats, although in these studies it was postulated that this reduction was mediated by inhibition of the renin-angiotensin system and not a direct effect of vitamin D (Li et al. 2002, Zhang et al. 2008). In addition, Aschenbrenner et al. (2001) reported that 1,25D treated rats had a significant reduction of TGFB1 in vivo, in agreement with our in vitro experiments, although RT-PCR demonstrated no difference in TGFB1 mRNA expression suggesting their findings were mediated through nongenomic pathways. 
A

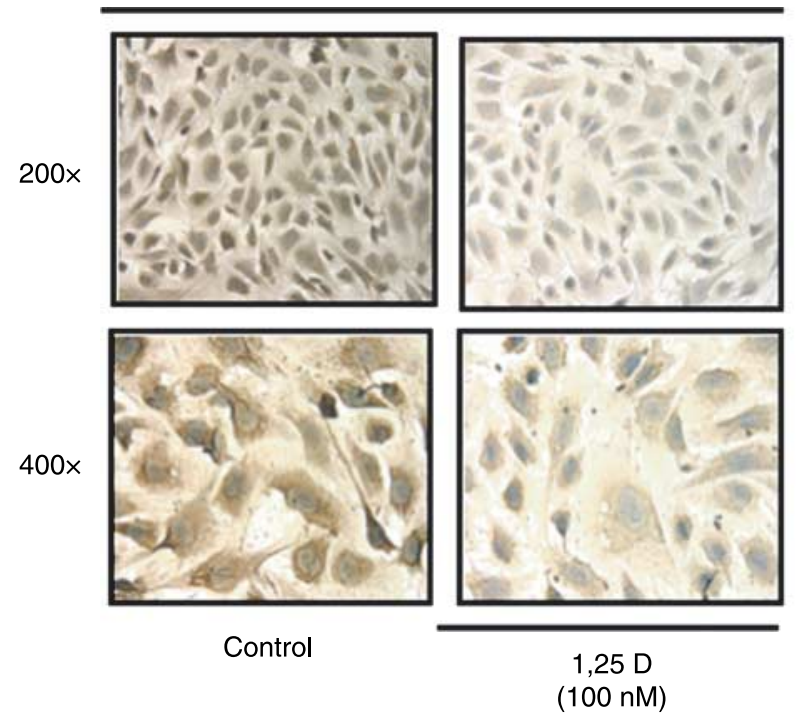

B

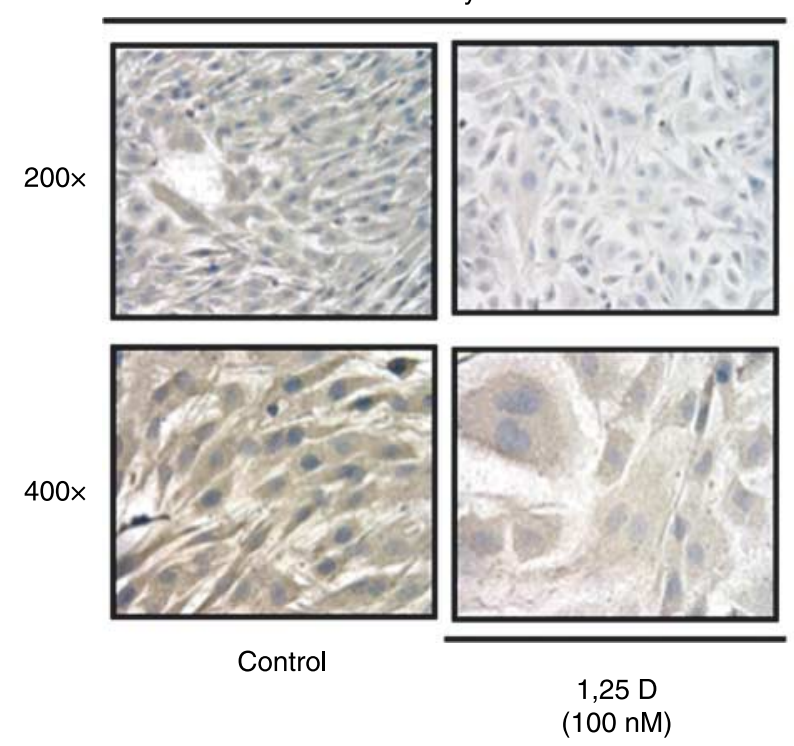

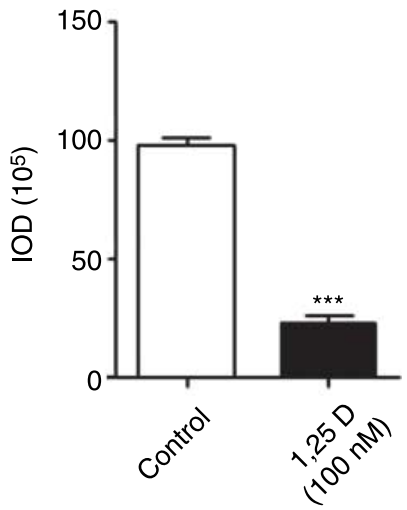

Collagen III

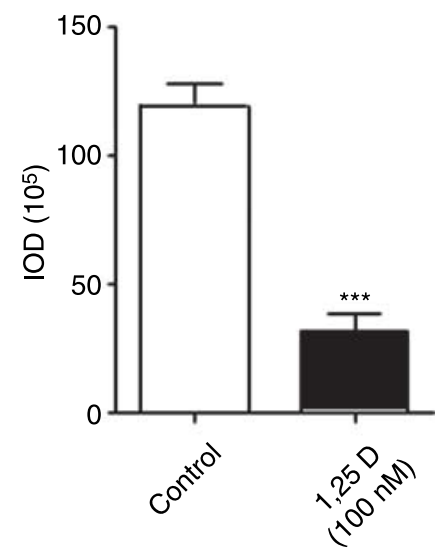

Figure 7 Effects of 1,25D on the expression of collagen III in C3H 10T1/2 cells. Cultures of C3H 10T1/2 cells were treated as in Fig. 1 and incubated with or without 1,25D (100 nM) for $24 \mathrm{~h}$ and 4 days. Immunocytochemistry for collagen III were performed at $24 \mathrm{~h}(\mathrm{~A})$ and 4 days (B) on eight-well removable chambers slides. Mean \pm s.E.M. corresponds to experiments done in triplicates of the integrated optical density (IOD) by quantitative image analysis $* * * P<0 \cdot 001$.

Our findings indicate that an early $(24 \mathrm{~h})$ and late $(4$ and 7 days) VDR mediated mechanism induces the suppression of TGFB1 and SERPINE1. Nevertheless, continuous incubation (4 and 7 days) with 1,25D to our cell cultures decreased the expression of the products that ultimately define a fibrotic process, which is collagen expression (Bhogal et al. 2005, Attallah et al. 2007). We observed a substantial decrease in collagen I, collagen III expression, and many other collagen isoforms at early $(24 \mathrm{~h})$ and late time points ( 4 and 7 days) after continuous incubation with vitamin D.
In addition to the inhibitory effects on the expression of profibrotic factors and collagen expression, 1,25D also induces upregulation of antifibrotic factors. Of particular interest is the increased expression of BMP7, a bone morphogenic protein factor that has been shown to protect against diabetic nephropathy in humans (Wang et al. 2006), and, in in vitro studies to be a potent antagonist of TGFB1 mediated fibrotic effects on renal cells (Gould et al. 2002, Patel \& Dressler 2005, Zhang et al. 2005), including TGFB1 induced epithelial-to-mesenchymal transition 
A

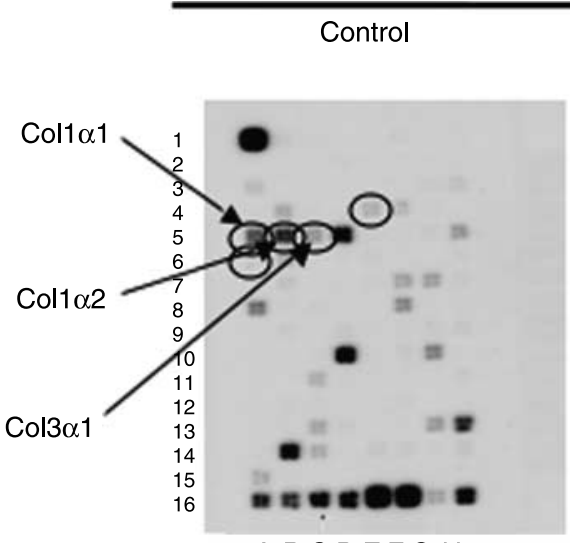

A B C DEFGH
$1,25 \mathrm{D}$

$(100 \mathrm{nM})$

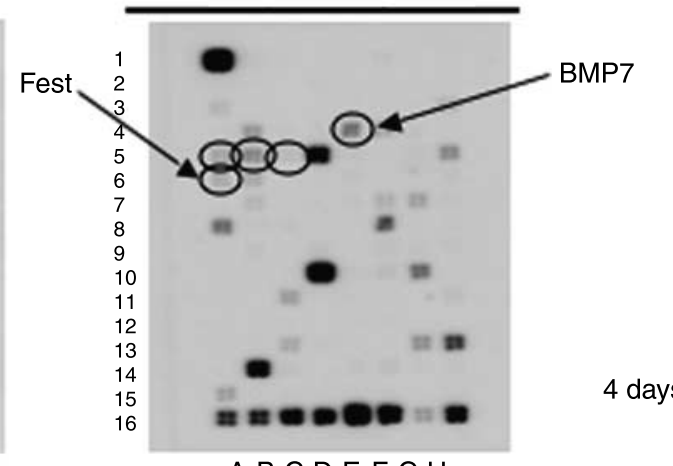

A B C DEFGH

B

Osteogenesis

DNA microarray
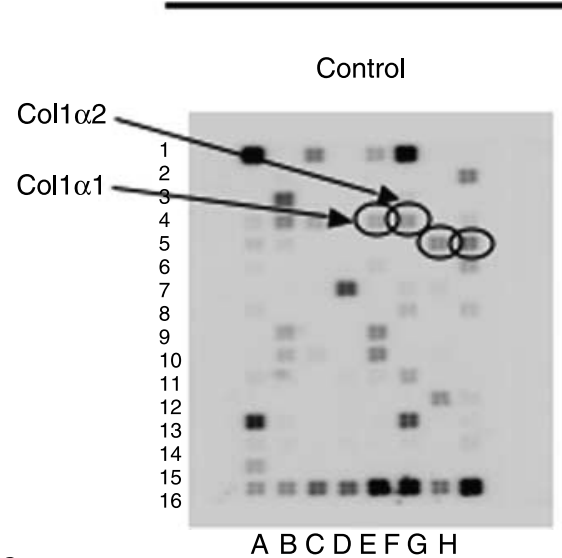

$1,25 \mathrm{D}$

$(100 \mathrm{nM})$

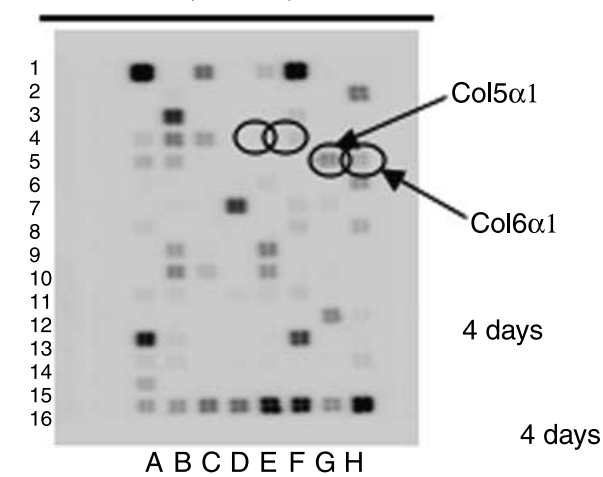

A B C D E F G

4 days

\begin{tabular}{|c|c|c|}
\hline Symbol & Description & $\begin{array}{c}\text { DNA microarray } \\
\text { Ratios (4 days) }\end{array}$ \\
\hline BMP4 & Bone morphogenetic protein 4 & +1.75 \\
\hline Col1 $\alpha 1$ & Procollagen, type I, $\alpha 1$ & -2.1 \\
\hline Col1 $\alpha 2$ & Procollagen, type I, $\alpha 2$ & -2.03 \\
\hline Col3 $\alpha 1$ & Procollagen, type III, $\alpha 1$ & -1.96 \\
\hline Col5 $\alpha 1$ & Procollagen, type V, $\alpha 1$ & -2.2 \\
\hline Col6 $\alpha 1$ & Procollagen, type VI, $\alpha 1$ & -2.1 \\
\hline Col6 $\alpha 2$ & Procollagen, type VI, $\alpha 2$ & -2.5 \\
\hline Fst & & Folllstatin \\
\hline MMP8 & Matrix metalloproteinase 8 & +3.36 \\
\hline BMP7 & Bone morphogenetic protein 7 & +2.35 \\
\hline
\end{tabular}


Table 1 Effects of 1,25D on the transcriptional expression of different collagen isoforms and other and antifibrotic genes in C3H 10T1/2 cells by real-time PCR arrays

\section{Description}

Symbol
BMP4
BMP6
Col1 $\alpha 1$
Col1 $\alpha 2$
Col2 $\alpha 1$
Col3 $\alpha 1$
Col5 $\alpha 1$
Col6 $\alpha 1$
Col6 62
Col10 21
Col12 $\alpha 1$
Col14 $\alpha 1$
Fst
BMP7
MMP8

Bone morphogenetic protein 4

Bone morphogenetic protein 6

Procollagen, type $\mathrm{I}, \alpha 1$

Procollagen, type I, $\alpha 2$

Procollagen, type II, $\alpha 1$

Procollagen, type III, $\alpha 1$

Procollagen, type IV, $\alpha 1$

Procollagen, type $\mathrm{VI}, \alpha 1$

Procollagen, type $\mathrm{VI}, \alpha 2$

Procollagen, type $X, \alpha 1$

Procollagen, type XI I, $\alpha 1$

Procollagen, type XIV, $\alpha 1$

Follistatin

Bone morphogenetic protein 7

Matrix metalloproteinase 8
Real-time PCR array ratios (24 h)

Real-time PCR array ratios (4 days)

$$
\begin{aligned}
& +2 \cdot 30 \\
& +1 \cdot 63 \\
& -1 \cdot 74 \\
& -2 \cdot 38 \\
& -2 \cdot 65 \\
& -2 \cdot 64 \\
& -2 \cdot 0 \\
& -3 \cdot 25 \\
& -3 \cdot 48 \\
& -2 \cdot 26 \\
& -1 \cdot 87 \\
& -1 \cdot 56 \\
& +6 \cdot 56 \\
& +4 \cdot 21 \\
& +3 \cdot 46
\end{aligned}
$$

Cultures of $\mathrm{C} 3 \mathrm{H}$ 10T1/2 cells were treated as in Fig. 1 and incubated with or without 1,25D (100 nM) for $24 \mathrm{~h}$ and 4 days. Total RNA was subjected to RT-realtime PCR by the RT ${ }^{2}$-PCR profiler TGFB1/BMP and osteogenesis array and the ratios between the 1,25D treated and 1,25D-untreated cells corrected by GAPDH were calculated for the assays performed in triplicates.

(EMT) of tubular epithelial cells (Zeisberg et al. 2004, 2005).

In addition, 1,25D induced upregulation of other key antifibrotic factors providing additional insights into the possible mechanism by which $1,25 \mathrm{D}$ promotes an antifibrotic phenotype. Incubation with 1,25D increased the expression of matrix metalloproteinase 8 (MMP-8), a potent collagen breakdown inducer, which cleaves collagen at a single site and renders it susceptible to degradation by other MMPs and proteases leading to a reversion of early fibrosis (Siller-Lopez et al. 2004, Newby 2007) and follistatin (Hill et al. 2002, Amthor et al. 2004, Kocamis et al. 2004), an important myostatin inhibitor. Myostatin is well known as a negative regulator of muscle mass (McPherron et al. 1997, Lee \& McPherron 2001, Lee 2004), and more recently described by us and others to be an important profibrotic factor (McCroskery et al. 2005, Zhu et al. 2007, Artaza et al. 2008a,b).

Thus, the antifibrotic effect observed in the current study in MMCs by the active form of vitamin D suggests a potential therapeutic or preventive capacity of vitamin D, consistent with similar suggestions for the antifibrotic potential of other proven antifibrotic therapies such as decorin (Li et al. 2004), Smad 7 cDNA (Forbes et al. 2006), follistatin (Aoki et al. 2005, Patella et al. 2006), and deacetylase inhibitors which induce follistatin expression (Iezzi et al. 2004).
Besides, the antifibrotic effect found in our study, incubation with 1,25D induces the expression of bone morphogenetic proteins, Bmp4 and Bmp6, which is in agreement with prior studies showing that $1,25 \mathrm{D}$ activates the BMP signaling pathway in MCF10 breast epithelial cells (Lee et al. 2006a,b) indicating a biological activity of $1,25 \mathrm{D}$ through VDR.

We believe that this study has clinical relevance, because it provides a clear and direct mechanistic explanation for the antifibrotic effect of $1,25 \mathrm{D}$ that is consistent with clinical observations that low levels of vitamin D are associated with increased cardiovascular risk factors (Martins et al. 2007, Wang et al. 2008) and increased mortality (Wolf et al. 2007, Melamed et al. 2008, Ravani et al. 2008), and the clinical observation that continuous administration of $1,25 \mathrm{D}$ attenuates the progression of glomerular and tubular interstitial fibrosis in patients with chronic kidney disease (Tian et al. 2007) and is associated with reduced mortality (Kovesdy et al. 2008, Wolf et al. 2008). Further studies are needed to establish a direct transcriptional control of these pro and antifibrotic genes by the 1,25D-VDR complexes, even though we demonstrated a parallel correlation between the expression of these genes and VDR at early time points suggesting a likely direct effect of the 1,25D-VDR complexes on transcriptional regulation of antifibrotic genes.

Figure 8 Effects of 1,25D on the transcriptional expression of different collagen isoforms and other fibrotic genes in C3H $10 \mathrm{~T} 1 / 2$ cells by DNA microarrays. Cultures of $\mathrm{C} 3 \mathrm{H} 10 \mathrm{~T} 1 / 2$ cells were treated as in Fig. 1 and incubated with or without 1,25D (100 nM) for 4 days on $75 \mathrm{~cm}^{2}$ flasks. Total RNA was isolated and subjected to DNA microarray analysis for genes related to the TGFB1/BMP signaling pathway (A) and for osteogenesis gene array (B). Representative membranes for each array are displayed. The circles show changes in the expression of some antifibrotic and profibrotic genes that were upregulated or downregulated by $1,25 \mathrm{D}$ treatment. (C) Ratios between the $1,25 \mathrm{D}$ treated and $1,25 \mathrm{D}$-untreated cells at 4 days, corrected by GAPDH were calculated for the assays performed in duplicates. 
We acknowledge that our current findings in a model of multipotent mesenchymal cells primed with azacytidine, which have been shown in humans (Adams et al. 2005) and in cell culture (Artaza et al. 2008a,b) to promote a fibrotic phenotype, may not accurately reflect what occurs in a clinical state. However, they have important implications for understanding the mechanistic pathways that are independent of calcium and parathyroid hormone, and may be useful in assessing potential future interventions with vitamin D analogs with a lesser calcemic effect than the parent compound that may have enhanced antifibrotic effects.

In summary, $1,25 \mathrm{D}$ (the active form of vitamin $\mathrm{D}$ ) induced a VDR-mediated antifibrotic signaling phenotype in multipotent mesenchymal cells characterized by a decreased expression of profibrotic markers and an increased expression of antifibrotic markers leading to an effective reduction in collagen expression. This study demonstrates direct pathways through which vitamin D modulates fibrosis, and supports the emerging clinical findings linking vitamin D deficiency to adverse cardiovascular health and other chronic medical conditions. The multipotent mesenchymal cell system may be a viable model for exploring parathyroid and calcemic independent non-classic effects of vitamin D and vitamin $\mathrm{D}$ analogs as potential therapeutic agents.

\section{Declaration of interest}

The authors declare that there is no conflict of interest that could be perceived as prejudicing the impartiality of this scientific work.

\section{Funding}

This work was supported by National Institutes of Health (NIH) - National Center for Research Resources/Research Centers in Minority Institutions grants RR019234 and RR003026 (JA and KN), and NIH - National Center on Minority Health \& Health Disparities grants MD000545 (JA) and MD00182 (KN).

\section{References}

Adams CD, Szumita PM, Baroletti SA \& Lilly CM 2005 Azacitidine-induced interstitial and alveolar fibrosis in a patient with myelodysplastic syndrome. Pharmacotherapy 25 765-768.

Amthor H, Nicholas G, McKinnell I, Kemp CF, Sharma M, Kambadur R \& Patel K 2004 Follistatin complexes myostatin and antagonises myostatinmediated inhibition of myogenesis. Developmental Biology 270 19-30.

Aoki F, Kurabayashi M, Hasegawa Y \& Kojima I 2005 Attenuation of bleomycin-induced pulmonary fibrosis by follistatin. American Journal of Respiratory and Critical Care Medicine 172 713-720.

Artaza JN, Bhasin S, Mallidis C, Taylor W, Ma K \& Gonzalez-Cadavid NF 2002 Endogenous expression and localization of myostatin and its relation to myosin heavy chain distribution in $\mathrm{C} 2 \mathrm{C} 12$ skeletal muscle cells. Journal of Cellular Physiology 190 170-179.

Artaza JN, Bhasin S, Magee TR, Reisz-Porszasz S, Shen R, Groome NP, Meerasahib MF \& Gonzalez-Cadavid NF 2005 Myostatin inhibits myogenesis and promotes adipogenesis in $\mathrm{C} 3 \mathrm{H} 10 \mathrm{~T}(1 / 2)$ mesenchymal multipotent cells. Endocrinology 146 3547-3557.

Artaza JN, Braga M \& Norris KC 2008a $1 \alpha, 25-(\mathrm{OH})_{2} \mathrm{D}_{3}(1,25 \mathrm{D})$ inhibits cell proliferation and promotes cell cycle arrest without inducing apoptosis in multipotent cells. Journal of Investigative Medicine 56 219-220 (Meeting Abstract 348).
Artaza JN, Singh R, Ferrini MG, Braga M, Tsao J \& Gonzalez-Cadavid NF 2008 b Myostatin promotes a fibrotic phenotypic switch in multipotent C3H 10T1/2 cells without affecting their differentiation into myofibroblasts. Journal of Endocrinology 196 235-249.

Aschenbrenner JK, Sollinger HW, Becker BN \& Hullett DA 2001 1,25$(\mathrm{OH}(2)) \mathrm{D}(3)$ alters the transforming growth factor beta signaling pathway in renal tissue. Journal of Surgical Research 100 171-175.

Attallah AM, Mosa TE, Omran MM, Abo-Zeid MM, El-Dosoky I \& Shaker YM 2007 Immunodetection of collagen types I, II, III, and IV for differentiation of liver fibrosis stages in patients with chronic HCV. Journal of Immunoassay \& Immunochemistry 28 155-168.

Bhogal RK, Stoica CM, McGaha TL \& Bona CA 2005 Molecular aspects of regulation of collagen gene expression in fibrosis. Journal of Clinical Immunology 25 592-603.

Brackman D, Lillehaug JR, Aksnes L \& Aarskog D 1993 Modulation of cell proliferation and cell cycle, and inhibition of cytokinesis by 1,25dihydroxyvitamin D3 in C3H/10T1/2 fibroblasts. Journal of Steroid Biochemistry and Molecular Biology 46 155-162.

Brown AJ 1998 Vitamin D analogues. American Journal of Kidney Diseases 32 S25-S39.

Carlberg C, Quack M, Herdick M, Bury Y, Polly P \& Toell A 2001 Central role of VDR conformations for understanding selective actions of vitamin D(3) analogues. Steroids 66 213-221.

Casteels K, Waer M, Bouillon R, Depovere J, Valckx D, Laureys J \& Mathieu C 1998 1,25-Dihydroxyvitamin D3 restores sensitivity to cyclophosphamide-induced apoptosis in non-obese diabetic (NOD) mice and protects against diabetes. Clinical and Experimental Immunology 112 181-187.

Dusso AS \& Brown AJ 1998 Mechanism of vitamin D action and its regulation. American Journal of Kidney Diseases 32 S13-S24.

Dusso AS, Thadhani R \& Slatopolsky E 2004 Vitamin D receptor and analogs. Seminars in Nephrology (in press).

Dusso AS, Brown AJ \& Slatopolsky E 2005 Vitamin D. American Journal of Physiology. Renal Physiology 289 F8-F28.

Eddy AA \& Fogo AB 2006 Plasminogen activator inhibitor-1 in chronic kidney disease: evidence and mechanisms of action. Journal of the American Society of Nephrology 17 2999-3012.

Fallowfield JA, Kendall TJ \& Iredale JP 2006 Reversal of fibrosis: no longer a pipe dream? Clinics in Liver Disease 10 481-497.

Feldman D, Pike JW \& Glorieux FH 2005 Vitamin D. edn 2, (ch 11), San Diego, CA: Elsevier Academic Press.

Forbes D, Jackman M, Bishop A, Thomas M, Kambadur R \& Sharma M 2006 Myostatin auto-regulates its expression by feedback loop through Smad7 dependent mechanism. Journal of Cellular Physiology 206 264-272.

Gharaee-Kermani M, Gyetko MR, Hu B \& Phan SH 2007 New insights into the pathogenesis and treatment of idiopathic pulmonary fibrosis: a potential role for stem cells in the lung parenchyma and implications for therapy. Pharmaceutical Research 24 819-841.

Giovannucci E 2008 Vitamin D and cancer incidence in the Harvard cohorts. Annals of Epidemiology (in press).

Gould SE, Day M, Jones SS \& Dorai H 2002 BMP-7 regulates chemokine, cytokine, and hemodynamic gene expression in proximal tubule cells. Kidney International 61 51-60.

Henderson NC \& Iredale JP 2007 Liver fibrosis: cellular mechanisms of progression and resolution. Clinical Science 112 265-280.

Hill JJ, Davies MV, Pearson AA, Wang JH, Hewick RM, Wolfman NM \& Qiu Y 2002 The myostatin propeptide and the follistatin-related gene are inhibitory binding proteins of myostatin in normal serum. Journal of Biological Chemistry 277 40735-40741.

Iezzi S, Di Padova M, Serra C, Caretti G, Simone C, Maklan E, Minetti G, Zhao P, Hoffman EP, Puri PL et al. 2004 Deacetylase inhibitors increase muscle cell size by promoting myoblast recruitment and fusion through induction of follistatin. Developmental Cell 6 673-684.

Iredale JP 2007 Models of liver fibrosis: exploring the dynamic nature of inflammation and repair in a solid organ. Journal of Clinical Investigation 117 $539-548$.

Kisseleva T \& Brenner DA 2006 Hepatic stellate cells and the reversal of fibrosis. Journal of Gastroenterology and Hepatology 21 S84-S87. 
Kocamis H, Gulmez N, Aslan S \& Nazli M 2004 Follistatin alters myostatin gene expression in C2C12 muscle cells. Acta Veterinaria Hungarica 52 135-141.

Kovesdy CP, Ahmadzadeh S, Anderson JE \& Kalantar-Zadeh K 2008 Association of activated vitamin $\mathrm{D}$ treatment and mortality in chronic kidney disease. Archives of Internal Medicine 168 397-403.

Lee SJ 2004 Regulation of muscle mass by myostatin. Annual Review of Cell and Developmental Biology 20 61-86.

Lee SJ \& McPherron AC 2001 Regulation of myostatin activity and muscle growth. PNAS 98 9306-9311.

Lee HJ, Liu H, Goodman C, Ji Y, Maehr H, Uskokovic M, Notterman D, Reiss M \& Suh N 2006 a Gene expression profiling changes induced by a novel Gemini Vitamin D derivative during the progression of breast cancer. Biochemical Pharmacology 72 332-343.

Lee HJ, Wislocki A, Goodman C, Ji Y, Ge R, Maehr H, Uskokovic M, Reiss M \& Suh N 2006b A novel vitamin D derivative activates bone morphogenetic protein signaling in MCF10 breast epithelial cells. Molecular Pharmacology 69 1840-1848.

Li YC, Kong J, Wei M, Chen ZF, Liu SQ \& Cao LP 2002 1,25Dihydroxyvitamin $\mathrm{D}(3)$ is a negative endocrine regulator of the reninangiotensin system. Journal of Clinical Investigation 110 229-238.

Li Y, Foster W, Deasy BM, Chan Y, Prisk V, Tang Y, Cummins J \& Huard J 2004 Transforming growth factor-beta1 induces the differentiation of myogenic cells into fibrotic cells in injured skeletal muscle: a key event in muscle fibrogenesis. American Journal of Pathology 164 1007-1019.

Malluche HH, Mawad H \& Koszewski NJ 2002 Update on vitamin D and its newer analogues: actions and rationale for treatment in chronic renal failure. Kidney International 62 367-374.

Martins D, Wolf M, Pan D, Zadshir A, Tareen N, Thadhani R, Felsenfeld A, Levine B, Mehrotra R \& Norris K 2007 Prevalence of cardiovascular risk factors and the serum levels of 25-hydroxyvitamin D in the United States: data from the Third National Health and Nutrition Examination Survey. Archives of Internal Medicine 167 1159-1165.

Mathieu C, Waer M, Laureys J, Rutgeerts O \& Bouillon R 1994 Prevention of autoimmune diabetes in NOD mice by 1,25 dihydroxyvitamin D3. Diabetologia 37 552-558.

Mauviel A 2005 Transforming growth factor-beta: a key mediator of fibrosis. Methods in Molecular Medicine 117 69-80.

McCroskery S, Thomas M, Platt L, Hennebry A, Nishimura T, McLeay L, Sharma M \& Kambadur R 2005 Improved muscle healing through enhanced regeneration and reduced fibrosis in myostatin-null mice. Journal of Cell Science 118 3531-3541.

McPherron AC, Lawler AM \& Lee SJ 1997 Regulation of skeletal muscle mass in mice by a new TGF-beta superfamily member. Nature 387 83-90.

Melamed ML, Michos ED, Post W \& Astor B 2008 25-Hydroxyvitamin D levels and the risk of mortality in the general population. Archives of Internal Medicine 168 1629-1637.

Newby AC 2007 Metalloproteinases and vulnerable atherosclerotic plaques. Trends in Cardiovascular Medicine 17 253-258 (Review).

Patel SR \& Dressler GR 2005 BMP7 signaling in renal development and disease. Trends in Molecular Medicine 11 512-518.

Patella S, Phillips DJ, Tchongue J, de Kretser DM \& Sievert W 2006 Follistatin attenuates early liver fibrosis: effects on hepatic stellate cell activation and hepatocyte apoptosis. American Journal of Physiology. Gastrointestinal and Liver Physiology 290 G137-G144.

Pittenger MF \& Martin BJ 2004 Mesenchymal stem cells and their potential as cardiac therapeutics. Circulation Research 95 9-20.

Rabbany SY, Heissig B, Hattori K \& Rafii S 2003 Molecular pathways regulating mobilization of marrow-derived stem cells for tissue revascularization. Trends in Molecular Medicine 9 109-117.

Ravani P, Malberti F, Tripepi G, Pecchini P, Cutrupi S, Pizzini P, Mallamaci F \& Zoccali C 2008 Vitamin D levels and patient outcome in chronic kidney disease. Kidney International (in press).

Repo JM, Rantala IS, Honkanen TT, Mustonen JT, Kööbi P, Tahvanainen AM, Niemelä OJ, Tikkanen I, Rysä JM, Ruskoaho HJ et al. 2007 Paricalcitol aggravates perivascular fibrosis in rats with renal insufficiency and low calcitriol. Kidney International 72 977-984.
Siller-Lopez F, Sandoval A, Salgado S, Salazar A, Bueno M, Garcia J, Vera J, Galvez J, Hernandez I, Ramos M et al. 2004 Treatment with human metalloproteinase- 8 gene delivery ameliorates experimental rat liver cirrhosis. Gastroenterology 126 1122-1133.

Singh R, Artaza JN, Taylor WE, Gonzalez-Cadavid NF \& Bhasin S 2003 Androgens stimulate myogenic differentiation and inhibit adipogenesis in C3H 10T1/2 pluripotent cells through an androgen receptor-mediated pathway. Endocrinology 144 5081-5088.

Schmittwolf C, Kirchhof N, Jauch A, Dürr M, Harder F, Zenke M \& Müller AM 2005 In vivo haematopoietic activity is induced in neurosphere cells by chromatin-modifying agents. EMBO Journal 24 554-566.

Tan X, Li Y \& Liu Y 2006 Paricalcitol attenuates renal interstitial fibrosis in obstructive nephropathy. Journal of the American Society of Nephrology 17 3382-3393.

Tan X, Li Y \& Liu Y 2007 Therapeutic role and potential mechanisms of active vitamin D in renal interstitial fibrosis. Journal of Steroid Biochemistry and Molecular Biology 103 491-496.

Tian J, Liu Y, Williams LA \& de Zeeuw D 2007 Potential role of active vitamin $\mathrm{D}$ in retarding the progression of chronic kidney disease. Nephrology, Dialysis, Transplantation 22 321-328.

Wang S, de Caestecker CM, Kopp J, Mitu G, Lapage J \& Hirschberg R 2006 Renal bone morphogenetic protein-7 protects against diabetic nephropathy. Journal of the American Society of Nephrology $172504-2512$.

Wang TJ, Pencina MJ, Booth SL, Jacques PF, Ingelsson E, Lanier K, Benjamin EJ, D'Agostino RB, Wolf M \& Vasan RS 2008 Vitamin D deficiency and risk of cardiovascular disease. Circulation 117 503-511.

Willis BC, duBois RM \& Borok Z 2006 Epithelial origin of myofibroblasts during fibrosis in the lung. Proceedings of the American Thoracic Society 3 377-382.

Wolf M, Shah A, Gutierrez O, Ankers E, Monroy M, Tamez H, Steele D, Chang Y, Camargo CA Jr, Tonelli M et al. 2007 Vitamin D levels and early mortality among incident hemodialysis patients. Kidney International 72 1004-1013.

Wolf M, Betancourt J, Chang Y, Shah A, Teng M, Camargo CA, Melamed M, Norris K, Stampfer MJ, Powe NR et al. 2008 Impact of activated vitamin D and race on survival among hemodialysis patients. Journal of the American Society of Nephrology 19 1379-1388.

Wu-Wong JR, Nakane M \& Ma J 2006 Effects of vitamin D analogs on the expression of plasminogen activator inhibitor-1 in human vascular cells. Thrombosis Research 118 709-714.

Wynn TA 2007 Common and unique mechanisms regulate fibrosis in various fibroproliferative diseases. Journal of Clinical Investigation 117 524-529.

Zehnder D, Bland R, Williams MC, McNinch RW, Howie AJ, Stewart PM \& Hewison M 2001 Extrarenal expression of 25-hydroxyvitamin D(3)-1 alphahydroxylase. Journal of Clinical Endocrinology and Metabolism 86 888-894.

Zeisberg M, Muller GA \& Kalluri R 2004 Are there endogenous molecules that protect kidneys from injury? The case for bone morphogenic protein-7 (BMP-7) Nephrology, Dialysis, Transplantation 19 759-761.

Zeisberg M, Shah AA \& Kalluri R 2005 Bone morphogenic protein-7 induces mesenchymal to epithelial transition in adult renal fibroblasts and facilitates regeneration of injured kidney. Journal of Biological Chemistry $\mathbf{2 8 0}$ 8094-8100.

Zhang XL, Selbi W, de la Motte MC, Hascall V \& Phillips AO 2005 Bone morphogenic protein-7 inhibits monocyte-stimulated TGF-beta1 generation in renal proximal tubular epithelial cells. Journal of the American Society of Nephrology 16 79-89.

Zhang Z, Sun L, Wang Y, Ning G, Minto AW, Kong J, Quigg RJ \& Li YC 2008 Renoprotective role of the vitamin $\mathrm{D}$ receptor in diabetic nephropathy. Kidney International 73 163-171.

Zhu J, Li Y, Shen W, Qiao C, Ambrosio F, Lavasani M, Nozaki M, Branca MF \& Huard J 2007 Relationships between transforming growth factor-beta1, myostatin, and decorin: implications for skeletal muscle fibrosis. Journal of Biological Chemistry 282 25852-25863.

\section{Received in final form 14 October 2008 \\ Accepted 21 November 2008}

Made available online as an Accepted Preprint 25 November 2008 